\title{
Title: The role of drug users' advocacy group in changing the dynamics of life in the Downtown Eastside of Vancouver, Canada
}

\author{
Ehsan Jozaghi ${ }^{1}$ \\ Pre-publication version 2013 \\ Published in 2014 \\ Journal of Substance Use, 19(1-2): 213-218
}

To link to this article: https://doi.org/10.3109/14659891.2013.775608

${ }^{1}$ School of Criminology, Simon Fraser University, Burnaby, British Columbia, Canada

\section{Keywords}

VANDU, Downtown Eastside of Vancouver, injection drug users

\section{Declaration of interest}

The author reports no conflicts of interest. The author alone is responsible for the content and writing of the paper. 


\title{
The role of drug users' advocacy group in changing the dynamics of life in the Downtown Eastside of Vancouver, Canada
}

\author{
Abstract \\ The Downtown Eastside (DTES) of Vancouver, Canada, has been the epicentre of HIV \\ and drug overdose related to injection drug users (IDUs) since the mid1990s. In \\ response to growing government inaction, a drug user-run organization known as \\ Vancouver Area Network of Drug User (VANDU) was formed. This study was \\ conducted to capture the genesis and influence of VANDU over the past 14 years in \\ shaping the neighbourhood. Semi-structured qualitative interviews were conducted with \\ purposively chosen sample of 11 VANDU board members and those attending the \\ services. Interviews were transcribed verbatim and analysed thematically using NVivo 9 \\ software. Participants' narratives indicate that VANDU has been instrumental in \\ improving conditions of the DTES, altering the risky injection behaviour of its members. \\ Moreover, VANDU has given a voice to the most marginalized members of society who \\ otherwise would not be represented. Findings from this study highlight the important \\ role that a drug user organization can play in creating new physical and conceptual \\ space.
}




\section{The role of drug users' advocacy group in changing the dynamics of life in the Downtown Eastside of Vancouver, Canada}

\section{Introduction}

According to Barnes \& Sutton (2009), the history of Vancouver's Downtown Eastside (DTES) began more than 100 years ago when the neighbourhood was the city's commercial core for culture, finance and retailing. This area of Vancouver was lively, dynamic and only blocks away from office towers that were the highest in the British Empire (Barnes \& Sutton, 2009). However, shortly after the Second World War, the DTES became a haven for the most marginalized population (Andresen \& Jozaghi, 2012). Dooling \& Rachlis (2010) describe how the DTES area around East Hastings became a refuge for unemployed men who were drawn to the area by cheap housing and cheap liquor. By 1960, the housing that remained predominately comprised single room occupancy hotel rooms (Dooling \& Rachlis, 2010).

In the 1960s and 1970s, heroin and later crack cocaine joined alcohol as problems facing this 10-block neighbourhood (Jozaghi, 2012). With high concentrations of injection drug users (IDUs), the mentally ill, the homeless, the elderly, the sex workers, the unemployed, the troubled youth and immigrants, the neighbourhood has been identified as the most impoverished urban neighbourhood in Canada (Hollands et al., 2009). Presently it is estimated that out of 8000 IDUs who reside in Vancouver, 4700 reside in the DTES (Maas et al., 2007).

Consequently, the DTES has a denser population of IDUs than any other neighbourhood in Canada, which has compounded the risk of HIV, Hepatitis C (HCV) and overdose deaths (Jozaghi, 2012). In fact, an explosive HIV and HCV epidemic in the late 1990s was the highest in the Western world, rivalling third world countries such as Botswana(Jozaghi, 2012; Tyndall et al., 2001).

Vancouver's DTES also documented an explosive rate of overdose death related to illicit drugs during the late 1990s (Fischer et al., 2000). In response to these concerns and a general lack of public health interventions for IDUs in the DTES, former and current drug users mobilized themselves in an effort to prevent the ongoing spread of HIV and overdose among their peers (Hayashi et al., 2010; Wood et al., 2003). Their efforts led to the creation of the Vancouver Area Network of Drug Users (VANDU) in 1997 (Wood et al., 2003). For their direct action on HIV/AIDS, VANDU was the recipient of an international human rights award (Kerr et al., 2006). Previous studies in North America have shown that drug user organizations can help extend the reach and effectiveness of harm reduction programs (Broadhead et al., 1995; Cottier et al., 1998; Grund et al., 1992). According to Broadhead et al. (1998), countries with effective community outreach and peer-work have been able to keep their HIV prevalence low. The present study sought to assess how drug user organizations such as VANDU intervene to help shape the neighbourhoods and capture the transformative role of peer led intervention in the lives of IDUs in the DTES.

\section{Methods}

VANDU operates a storefront office in the DTES along East Hastings Street and has over 1300 members and over 800 volunteers (Small et al., 2012; Wood et al., 2003). VANDU is overseen by a Board of Directors comprised current and former users (Small et al., 2012). According to Wood et al. (2003), VANDU has been recognized as one the most successful peer- based drug user organization internationally. VANDU is funded through Vancouver Coastal Health with an annual operating budget of \$200,000 (Austin, 2012). VANDU operates a variety of programs in the DTES that are tailored towards drug-user-led harm reduction programs (Kerr et al., 2005, 2006).

This study was approved by Simon Fraser University Research Ethics Board. In accordance with VANDU's philosophy and its members' demands that all projects directly involve them, the researcher employed a communitybased case study methodology to achieve the study objectives. As a result, the study was also approved by VANDU's Executive Board. Beginning in September 2012, participants living in DTES, who had volunteered at 


\section{Original Article}

VANDU in the previous month, were recruited to participate in the study. Participants were eligible for the study if they were 19 years or older and provided oral consent. To protect confidentiality, all identifying information was removed from interview transcripts and all names used in this paper are pseudonyms.

The researcher and the board members had a pre-existing relationship that was established during the researcher's previous volunteer work in the DTES. ${ }^{1}$ To protect the confidentiality of the seven board members, only the demographic characteristics of the four IDUs who used the services at VANDU and participated in the study are shown in Table 1. Participants were told by the board members that the researcher was a student. None of those who were invited to participate refused. In fact, the referral by the VANDU board member and prior approval by the board allowed the participants to feel comfortable and open up more easily about their experiences.

Open-ended, semi-structured interviews were facilitated through the use of an interview guide. Responses were audio recorded and later transcribed verbatim using Dragon Naturally Speaking software and techniques described in Palys \& Atchisonm (2012). The Interview guide for VANDU board members focused on their work as a peer IDU at VANDU, the impact they believe their work has had in the community, the DTES situation prior to VANDU, the DTES after the establishment of VANDU and suggestions related to the ways risky behaviours could be reduced.

In all the interviews, topics came out of natural conversation and, as suggested by Berg (2009), deviations were explored as they arose. Interviews ranged from 20 to $70 \mathrm{~min}$. The qualitative data were reviewed, and all text segments were subsequently subjected to a thematic analysis using NVivo 9 software. Twenty-two types of nodes were created. A "tree" node was created for general themes resulting from an inductive search. A "free" node was deductive or emergent, and came from general observations, which resulted in more specific categories. Free nodes were created after tree nodes were searched. Silverman \& Marvasti (2008) warn of the tendency for coding schemes to become "powerful conceptual grid[s] from which it is difficult to escape" (p. 225).

A word frequency query was also completed to view the most frequently used words. At a later date, the most frequently reported words were used to search the transcript for common themes and phrases. This organization and analysis of the data allowed the most dominant themes to be identified. Interviews were listened to several times before importing and transcribing them in the NVivo 9 software.

\section{Findings}

\section{The DTES change}

The most common theme was related to the dire situation in the DTES prior to the establishment of VANDU. As one of the board members who has lived in the DTES for more than 35 years describes:

Back then 30 years ago there was no needle depot there was no InSite there was no VANDU ... You hold onto [your needle] as much as you could, sometimes you give it to your buddies to use because they didn't have one. . . So many people died or contracted HIV and hepatitis C. You had to buy [needles] on the street for 5 to 10 bucks back then in 1983 . . . Nobody knew what harm reduction was. It was like sucking water out of the mud. You take your chances. . . so many people died of overdose, people were dropping like flies. . .

You had 300 people in these alleys left and right doing dope back then 24 hours a day... they were selling dope and doing dope, defecating and urinating everywhere. .. you'd see people sharing needles all the time.

\footnotetext{
${ }^{1}$ The researcher volunteered in the Washington's Needle Depot in the Downtown Eastside for 2 years.
} 


\section{Original Article}

The board member's recollection is verified in overdose data assembled by Cain (1994), who notes the number of drug overdose death in Vancouver jumped from 18 in 1988 to over 200 in 1993. The rate of HIV/AIDS also increased dramatically, rising from $7 \%$ to as high as $23 \%$ (Roe, 2003). According to one of the co-founders of VANDU, it was the dire situation of the DTES, coupledwith grass root activism that helped to establish VANDU:

VANDU was basically formed by accident during our
activism ... We were part of the radical group of people
who were organizing and we decided to focus on the
drug issue in the downtown Eastside ... We got a small
grant ... and rented a little storefront. We saw how
many people were getting HIV and hepatitis and how
many people were dying of overdose so we opened up
the table right up at the corner of Main and Hastings
and we just started handing out rigs ... A lot of drug users
coming into the meeting said that they need to have a
place to inject safely and we started doing a guerilla
injection site.

According to Boyd et al. (2009), after VANDU received a modest grant from the Vancouver Health Board in 1998, it became the first public health supported organization of current and former drug users in North America. As Kerr et al. (2004) describe, a key part of the larger movement to establish a SIF in Vancouver involved the operation of illegal SIFs by local drug users and community activists such as VANDU that eventually forced the federal government to open North America's first sanctioned SIF. The group soon succeeded in raising funds to provide peer-based support to local IDUs in the DTES. For example, Wood et al. (2003) evaluation of VANDU's unsanctioned syringe distribution in front of Carnegie Community Centre found that the use of the exchange was strongly associated with higher rates of safe syringe disposal. According to one of the board members, establishing unsanctioned SIFs and the group's activism served to sustain pressure on policy makers to establish effective harm reduction programs in the DTES:

Our philosophy is that Canadians are normally good people and if they knew what was happening to drug users they would change their views so what we needed to do was to try to talk to the public and we did that with these demonstrations and we did get coverage. . . And then after all the overdose deaths in the Downtown Eastside we decided to put a thousand crosses in the Oppenheimer Park and also at the City Hall and it was a great coverage by the media and the newspapers. The media were able to take our message

to the people in Vancouver that there is something wrong in this area something needs to be done about it.

According to Kerr et al. (2006), VANDU also brought considerable attention to the issues facing local IDUs by demonstrating at Vancouver City Hall and the front steps of the BC Legislature. At both of these events, a large red banner with the phrase "The Killing Fields: Federal Action Now" was displayed (Kerr et al. 2006). VANDU also pleaded with city councillors and the mayor to do whatever they could to stop the unnecessary drug related death and HIV epidemic by "interrupting Council business one day by parading into Council chambers with a coffin and staging an impromptu speech" (Kerr et al. 2012, p. 114). However, the work of VANDU did not stop after the opening of InSite in 2003, as one of board members describes:

We still do a lot of work in the community ... we do a lot of activism like going to the City Hall fighting to change the speed limit in the Downtown Eastside from $50 \mathrm{~km}$ to $30 \mathrm{~km}$ because a lot of residents were getting hit when they were crossing the streets ... One of the biggest campaigns that was really good a few years 


\section{Original Article}

ago was the ticketing... The police handed out in one month 1100 tickets so we created this campaign so people would bring their tickets to us and we ended up having a working group that coordinated with the city and the Pivot Legal Society and the Crown; we had about 600 to 800 people with jaywalking tickets totally thrown out.

In addition to making the DTES safer for residents and reducing the ticketing, VANDU members have been involved in improving environmental conditions in the DTES. VANDU members are involved in alley patrols where they pick up garbage and needles in the DTES. According to one of the board members, they have also been involved in a campaign to force city hall to provide more public bathrooms for the homeless in the DTES:

So what happens is that a lot of people use the lanes for their bathrooms... so [a] lot of people don't have a home ... and ... most people try to find a dark place in the lane so people get ticketed for $\$ 200$ ticket for urinating in the lanes. . . we petitioned City Hall to spend some money to let us keep the washrooms in the downtown Eastside open at night there is one in the Oppenheimer Park, there is one in the Victory Square and there is one in the Pigeon Park. The city agreed to keep the washrooms open until midnight. They used to close between nine in the morning and seven at night ... Now they're open $24 \mathrm{hrs}$.

According to Latkin et al. (2005), changing the environmental conditions of the DTES by VANDU members through their activism may influence the general health of residents because characteristics of urban neighbourhoods such as physical decay, litter and human waste influences the feeling of hopelessness, stressors and helplessness.

\section{Changes in behaviour}

VANDU's impacts have been felt at the individual level as well by providing an avenue where members form friendships, access social support and make a difference in their community through volunteerism. For example, for one of the board members, VANDU has been about empowerment:

\footnotetext{
VANDU is all about empowerment ... and it's working with people and showing them that they're not a piece of shit, that ... there are people who care ... you feel that you're part of something bigger. . . most people in the Downtown Eastside are depression prone to very negative thinking so for me that was a hard thing to do because when I came in I was able to stand up and talk about my experience when I was molested as a child and how people come up to me afterwards and thanking me for saying that and say[ing] that it happened to [them] too. People will start talking about their own experience in an atmosphere around people that are nonjudgmental and very open and friendly and compassionate. . . now they feel better about themselves because they're able to talk about that and that's usually the biggest stumbling blocks for people moving on and reducing the drug use.
}

According to Boyd et al. (2009), a significant accomplishment of VANDU was to encourage its members to recognize that their lives have value, dignity, worth and to heal the misery that addicts have endured for more than a 


\section{Original Article}

century. For many of the participants who volunteer or participate in VANDU's activities, their work and involvement in their community has been a real life transformation. These transformations can sometimes translate into changes in drug using behaviour. As one of the board members describes:

I think our biggest contribution to the Downtown

Eastside has been the education part. We have been really successful and educating junkies regarding how to safely inject what not to do and how to save lives. I actually seen changes in people's behaviour injecting: they don't shake and bake anymore. Even one girl who told me she's been doing it for years, she now basically because of what I told her many times she will cook the dope up properly ... People don't share anymore ... . now most people have CPR training and VANDU boards and people that worked on the desk and in the injection room know how to revive someone from overdose situation.

Boyd et al. (2009) describe how user groups such as VANDU encourage "risk reduction among. . . IDUs, and disseminate information about availability of medical and other services" (p. 79). Consequently, it seems that peers have a far more overarching effect. Therefore, peers who work at VANDU can effectively address many of the micro-environmental factors that drive sharing behaviour or overdose risk and enhance individual ability to employ overdose prevention practices.

Furthermore, peers at VANDU play a substantial role in managing and reducing overdose within the street based drug scene of the DTES. According to one of the board members, VANDU is able to help the most marginalized IDUs:

Like we had the injection support team that traveled the alleys especially women who needed help, they have the highest HIV rate because they needed help to inject themselves and people usually take advantage of them. People were getting ripped off in the alleys: people put in a Gypsy switch when they're doctoring their friends and injecting their friends with water or dirty needle. And there, women were likely to be violated and they ask for help in the alleys in the Downtown Eastside.

Every step they had to make from getting their drugs to injecting was a step toward violence. So basically all of us got together and we decided to go on and travel the alleys and help people to inject.

VANDU also provides an unsanctioned injection room for people who require assistance injecting. The injection room also attracts people who are banned or do not like to travel to InSite. Monica, one of the participants who uses the services at VANDU, believes that its services have helped her to reduce her drug use:

It's helping me to get back on my feet slowly and getting involved in the society and I feel like I'm part of the Downtown Eastside community and I've been able to reduce my drug use because before I used to be jonesing all the time. Attending these meetings and saying that everybody else's doing the same. . . VANDU is helping me in so many areas emotionally. I am more stable. My self-esteem and just the people around [are] really helping me I'm thinking that I'm not alone. . . I'm here to participate. I'm totally 


\section{Original Article}

involved in the activities because its keeping me out of trouble and keeps me out of the drug.

Their new roles as a result of self-empowerment have the potential to mediate patterns of infectious disease and mortality, and eventually change lives amongst the most marginalized IDUs. The study conducted by Wood et al. (2003) reported that "drug user organizations can play a major role in reducing harm among their peers by reaching the highest risk drug users" (p. 455). Such marginalized groups, according to Wood et al. (2005), have been shown to be at an elevated risk of blood borne infections and overdose. Peers play an important role in initiating labelling, membership and shared values, which is a critical step towards a collective identity.

\section{Change in stigmatization}

In addition to changes at the micro (individual) and macro (community) levels in the DTES, VANDU has been able to transform the view of the general public about drug users and residents of the DTES. For example, according to one of the co-founders:

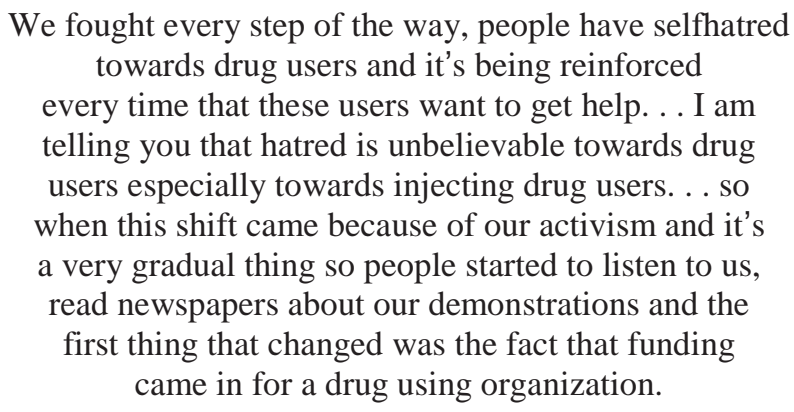

Recent research suggests that IDUs are dehumanized by others such as police officers, health care workers and the general public because they are often perceived as "the dregs of society who steal to support their behaviour and drug related illness" (Hippel \& Brener, 2012, p. 1030). A growing number of studies have suggested that stigma and discrimination may act as a key barrier to health access (Cohan et al., 2006; Hippel \& Brener, 2012). In fact, as one of the board members describes:

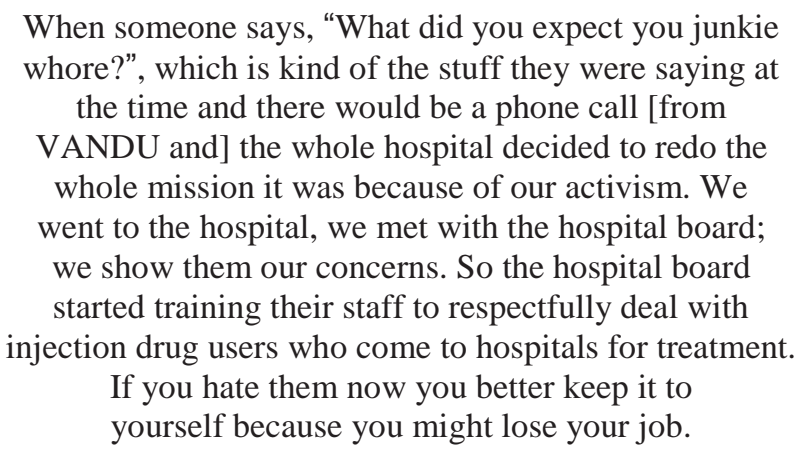

According to Boyd et al. (2009), the first task of VANDU when it was established was to "change the demonizing rhetoric they endured, using community meetings, demonstrations, education and fearlessness in the face of repression" (p. 43). The VANDU has also been advocating for residents of the DTES when dealing with the Vancouver police department. In many instances, VANDU members will help a complainant to find legal assistance. Their actions have forced the city and the police to change their practices. For example, according to one of the board members:

There was one guy who got four vending tickets. He was selling his stuff on the sidewalk just because either he was homeless or he was living in a building where there is no backyard. Because most people that have 


\section{Original Article}

backyards, they can sell their stuff in their backyards

like a garage sale or something; but people in the

Downtown Eastside don't have that luxury. So they

are forced to come to the street, but the police gives

them $\$ 250$ ticket ... So we took this issue to City Hall and we took this issue to the police board. And that's how we got the Sundays market close to pigeon Park on Carrel street. We are the organizing committee for [the] Sunday market.

VANDU has also been instrumental in giving voice to people in Vancouver who might have no other way to express themselves. VANDU has allowed IDUs to form a collective identity and be able to make a difference in the way they are treated by police, members of society and government organizations. For instance as Bryan declares:

We were involved last weekend with the Women's

March so every year we get involved with a different

demonstration. Few months ago there was an international police brutality day so it was basically VANDU who marched along the streets and we went to Main and Hastings and made a giant circle and cut off traffic and then we had. . . [an open forum] where people could come up and talk about their own experience with the police brutality. And then people could talk about what they could do to change this attitude of police towards injection drug users. We've done actions around methadone too.

According to Austin (2012), members of VANDU are very active politically and they have recently been protesting "in front of the Vancouver Police station on Cambie street over what they say is [Vancouver's city] council's misdirection of funds towards policing and a new roof for B.C. place, instead of [social] housing for [the] poor" (p. 1). In doing so, peers and drug user organizations in the DTES have countered stereotypical constructions of "the drug user" and the residents of the DTES who, according to Capitanio and Herek (1999) attracts particularly harsh condemnation. VANDU's activism in the DTES, according to Boyd et al. (2009), "can provide information about development in drug use that may be useful for the prevention of epidemics" (p. 79).

\section{Discussion}

A handful of studies have evaluated VANDU's programmes including its peer-run syringe exchange (Hayashi et al., 2010; Wood et al., 2003), harm reduction programmes (Kerr et al., 2006) and the injection support team (Small et al., 2012). Yet to date, there has been no systematic evaluation of VANDU's influence over the past 14 years of its operation in the DTES. The results from the current study suggest that VANDU has been able to reduce risky injection behaviour and reduce risk of overdose death by establishing unsanctioned SIF. The social support provided by a drug organization like VANDU, helps IDUs to maintain lower-risk injection behaviour. Therefore, social activism to embed safety norms among one's peers can help IDUs to avoid high risk situations (Friedman et al., 2011).

However, the most important role of VANDU that has not been discussed thus far in any peer reviewed studies has been its social activism. The significant success of VANDU has been to encourage its members that their life has value, worth and dignity (Boyd et al., 2009). Similar to Massey (1995) who provides examples about how the nature of labour process can have an important influence on location, I suggest that the creation of VANDU over the past 14 years has been powerful enough to contribute to change in key factors both at the micro and macro levels of life in the DTES. In effect according to Erikson (1961), "accumulation of decisions made by the community over a long period of time ... gradually gathers enough moral influence to serve as a precedent for future decisions" (p. 310). I suggest that each year of work and activism by members of VANDU brings with it potentially new social organization, new structural capacities and new overall positions for IDUs in society. 


\section{Original Article}

The new DTES represents new sets of power relations, new spatial forms of social organization, new dimensions of inequality and new relations of dimensions of dominance and dependence. Therefore, peer-work over the past 14 years in the DTES has contributed to the creation of new physical and conceptual space. In physical terms, the DTES has become cleaner and safer for its residents because of the availability of two injection facilities and more public bathrooms. According to Parkin \& Coomber (2009), IDUs reported a sense of shame and degradation in the practice of public drug use that is directly associated with the public injection environment. In conceptual terms, IDUs are less likely to experience discrimination by the city, hospital and police. Moreover, the residents in the new DTES are more likely to be involved in their civic issues and raise concerns in a new political arena. VANDU has given a voice to the most marginalized members of society who otherwise would not be represented.

Thus 14 years ago, a group of economically impoverished and courageous former and current drug users started an inspirational organization. Through education, community meetings and demonstrations, their first task was to change the demonizing rhetoric they endured (Boyd et al., 2009). They have not only been able to change the rhetoric but they have been able to reduce the misery that addicts have endured. Despite the challenges, they have been able to push the boundaries and continuously strive to represent the concerns of drug users. Today, more than 5000 IDUs of the DTES have a political voice that has been able to advocate for their rights in their immediate community and the community at large. Findings from this study highlight the important role that a drug user organization can play. 


\section{Original Article}

\section{References}

Andresen, M. A., \& Jozaghi, E. (2012). The point of diminishing returns: An examination of expanding

Vancouver's Insite. Urban Studies, 49(16), 3531-3544.

Austin, I. (2012, June 6). Drug-user group protests that cops are targeting poor. The Province, Retrieved October 12 , 2012 from:

http://www.theprovince.com/news/Drugpuserpgrouppprotestspthatpcopsptargetingppoor/6737323/story.html

Barnes, T., \& Sutton, T. (2009). Situating the new economy: Contingencies of regeneration and dislocation in Vancouver's inner city. Urban Studies, 46, 1247-1269.

Berg, B. L. (2009). Qualitative research methods for the social sciences. Toronto: Allyn \& Bacon.

Bourgois, P., Martinez, A., Kral, A., Edlin, B. R., Schonberg, J., \& Ciccarone, D. (2006). Reinterpreting ethnic patterns among white and African American men who inject heroin: A social science of medicine approach. PLoS Medicine, 10(3), 1805-1815.

Boyd, S., MacPherson, D., \& Osborn, B. (2009). Raise shit: Social action saving lives. Winnipeg: Fernwood Publishing.

Broadhead, R. S., Heckathorn, D. D., Grund, J. P., Stern, L. S., \& Anthony, D. L. (1995). Drug users versus outreach workers in combating AIDS: Preliminary results of peer-driven intervention. Journal of Drug Issues, 25(3), 531-564.

Broadhead, R. S., Heckathorn, D. D., Weakliem, D. L., et al. (1998). Harnessing peer networks as an instrument for AIDS prevention: Results from a peer-driven intervention. Public Health Reports, 113(1), 42-57.

Cain, J. V. (1994). The Cain report. British Columbia task force into illicit narcotic overdose deaths in British Columbia. Victoria, BC: BC Ministry of Health.

Capitanio, J. P., \& Herek, G. M. (1999). AIDS related stigma and attitudes toward injecting drug users among Black and White Americans. American Behavioral Scientist, 42, 1148-1161.

Cohan, D. A., Lutnick, P., Davidson, C., et al. (2006). Sex worker health: San Francisco style. Sexually Transmitted Infections, 82, 418-422.

Cottier, L. B., Compton, W. M., Abdallah, A., et al. (1998). Peer-delivered interventions reduce HIV risk behaviours among out-of-treatment drug abusers. Public Health Reports, 13(1), 31-41.

Dooling, K., \& Rachlis, M. (2010). Vancouver's supervised injection facility challenges Canada's drug laws. Canadian Medical Association Journal, 182(13), 1440-1444.

Erikson, K. T. (1961). Notes on the Sociology of deviance. Social Problems, 9(4), 307-314.

Fraser, S., \& Moore, D. (2008). Dazzled by unity? Order and chaos in public discourse on illicit drug use. Social Science and Medicine, 66, 740-752.

Friedman, S. R., Sandoval, M., Mateu-Gelabert, P., Meylakhs, P., \& Des Jarlais, D. C. (2011). Symbiotic goals and the prevention of blood-borne viruses among injection drug users. Substance Use \& Misuse, 46, 307-315.

Grund, J. P., Blanken, P., Adriaans, N. F., Kaplan, C. D., Barendregt, C., \& Meeuwsen, M. (1992). Reaching the unreached: Targeting hidden IDU populations with clean needles via known user groups. Journal of Psychoactive Drugs, 24(1), 41-47. 


\section{Original Article}

Hayashi, K., Wood, E., Wiebe, L., Qi, J., \& Kerr, T. (2010). An external evaluation of peer-run outreach-based syringe exchange in Vancouver, Canada. International Journal of Drug Policy, 21, 418-421.

Hippel, C. V., \& Brener, L. (2012). Specificity of discrimination: Does it matter from whence it coms? Journal of Applied social Psychology, 42(4), 1029-1042.

Hollands, H., Brox, A. C., Chang, A., et al. (2009). Correctable Visual impairment and its impact on quality of life in a marginalized Canadian neighbourhood. Canadian Journal of Ophthalmology, 44(1), 42-48.

Jozaghi, E. (2012). 'A little heaven in hell': The role of a supervised injection facility in transforming place. Urban Geography, 33(8), 1144-1162.

Kerr, T., MacPherson, D., \& Wood, E. (2012). Establishing North Americas first Safer injection facility: Lessons from the Vancouver experience. In A. Stephens (Ed.), Crossing Frontiers: International developments in the treatment of drug dependence (pp. 109-129). London: Pavillion Publishing.

Kerr, T., Oleson, M., \& Wood, E. (2004). Harm-reduction activism: A case study of an unsanctioned user-run safe injection site. Canadian HIV AIDS Policy Law Review, 9(2), 13-19.

Kerr, T., Oleson, M., Tyndall, M. W., Montaner, J., \& Wood, E. (2005). A description of peer-run supervised injection site for injection drug users. Journal of Urban Health, 82(2), 267-275.

Kerr, T., Small, W., Peeace, W., Douglas, D., Pierre, A., \& Wood, E. (2006). Harm reduction by a 'user run' organization: A case study of Vancouver area network of drug users. International Journal of Drug Policy, 17, 6169.

Latkin, C. A., Williams, C. T., Wang, J., \& Curry, A. D. (2005). Neighborhood social disorder as a determinant of drug injection behaviours: A structural equation modeling approach. Health Psychology, 24 (1), 96-100.

Maas, B., Fairbairn, N., Kerr, T., Li, K., Montaner, J., \& Wood, E. (2007). Neighbourhood and HIV infection among IDU: Place of residence independently predicts HIV infection among a cohort of injection drug users. Health \& Place, 13, 432-439.

Massey, D. (1995). Spatial division of labour: Social structures and the geography of production. London: Macmillan Press.

Miller, J. S. (1998). HIV, Hepatitis, and injection drug use in British Columbia: Pay now or pay later? Victoria, BC: B.C. Ministry of Health.

Palys, T., \& Atchisonm, C. (2012). Qualitative Research in the Digital Era: Obstacles and Opportunities. International Journal of Qualitative Methods, 11(4), 352-367.

Parkin, S., \& Coomber, R. (2009). Public injection and symbolic violence. Addiction Research and Theory, 17(4), $390-405$.

Roe, G. W. (2003). Harm reduction in an epidemic: The lost opportunities of the HIV/AIDs action plan in the Downtown Eastside, 1998 to 2000. Burnaby: Simon Fraser University.

Silverman, D., \& Marvasti, A. (2008). Doing qualitative research: A comprehensive guide. Los Angeles, CA: Sage Publications.

Small, M. L. (2009). 'How many cases do I need?': On science and the logic of case selection in field-based research. Ethnography, 10(1), 5-38.

Small, W., Wood, E., Tobin, D., Rikley, J., Lapushinsky, D., \& Kerr, T. (2012). The injection support team: A peerdriven program to address unsafe injecting in a Canadian setting. Substance Use \& Misuse, 47, 491-501. 
Stephens, R. C., Feutch, T. E., \& Rowan, S. W. (1991). Effects of an intervention program on AIDS-related drug and needle behavior among intravenous drug users. American Journal of Public Health, 81(5), 568-571.

Tyndall, M. W., Craib, K. J., Currie, S., Li, K., O’Shaughnessy, M. V., \& Schechter, M. T. (2001). Impact of HIV infection on mortality in a cohort of injection drug users. Journal of Acquired Immune Deficiency Syndrome, 28, 351-357.

Wood, E., Kerr, T., Spittal, P. M., et al. (2003). An external evaluation of peer-run "unsanctioned" syringe exchange program. Journal of Urban Health, 80(3), 455-464.

Wood, E., Tyndall, M. W., Li, K., et al. (2005). Do Supervised injection facilities attract higher-risk injection drug users? American Journal of Preventive Medicine, 29(2), 126-130. 